\title{
Ciltte Kserozis ile Ortaya Çıkan Çölyak Hastalığı: Olgu Sunumu
}

Celiac Disease That Occurs with Xerosis on The Skin: Case Report

\author{
Nilüfer Yılmaz ${ }^{1}$ (D) , Melike Arslan² (D) , Necati Balamtekin² (D), Ercan Çalışkan³ \\ 1 Çocuk Sağlığı ve Hastalıkları AD, Sağlık Bilimleri Üniversitesi, Gülhane Eğitim ve Araştırma Hastanesi, Ankara/Türkiye \\ 2 Çocuk Gastroenterolojisi BD, Çocuk Sağlığı ve Hastalıkları AD, Sağlık Bilimleri Üniversitesi, Gülhane Eğitim ve Araştırma Hastanesi, Ankara/Türkiye \\ 3 Deri ve Zührevi Hastalıklar AD, Sağlık Bilimleri Üniversitesi, Gülhane Eğitim ve Araştırma Hastanesi, Ankara/Türkiye
}

\section{özeT}

Çölyak hastalığı genetik olarak duyarlı kişilerde başlıca buğdaydaki gluten ve arpa, çavdar, yulaf gibi tahıllardaki gluten benzeri diğer tahıl proteinlerine karşı kalıcı intolerans olarak gelişen proksimal ince barsak hastalığıdır. Otoimmün mekanizmalar ile gelişir. Bir enteropati olarak bilinmesine rağmen son yıllarda ortaya konulan ve belirginleşen gastrointestinal sistem dışı bulguları ile her sistemin hastalı̆ı haline gelmiştir. Çölyak hastalığına eşlik edebilen mukokütanöz bulguların, otoimmün mekanizmalardan ve malabsorbsiyonun neden olduğu çoklu besin eksikliklerinden kaynaklandığı düşünülmektedir. Bu makalede kronik kserozis sebebiyle getirilen ve yapılan ileri değerlendirme neticesinde çölyak hastalığı tanısı konulan bir hasta sunulmuş ve literatür bilgileri ışı̆̆ında tartışılmıştır.

Anahtar Kelimeler: çölyak hastalığı, kserozis, çocuk

\section{ABSTRACT}

Celiac disease is a proximal small bowel disease in genetically susceptible individuals that develops as a permanent intolerance to gluten in wheat and other gluten-like grain proteins in cereals such as barley, rye and oats. It develops with autoimmune mechanisms. Although it is known as an enteropathy, it has become a disease of every system with the findings outside the gastrointestinal tract, which have been revealed and become evident in recent years. It is thought that mucocutaneous findings that may accompany celiac disease result from autoimmune mechanisms and multiple nutritional deficiencies caused by malabsorption. In this article, a patient who was brought for chronic xerosis and was diagnosed with celiac disease as a result of further evaluation was presented and discussed in the light of the literature.

Keywords: celiac disease, child, chronic xerosis

\section{Giriş}

Çölyak hastalı̆̆ı, duyarlı bireylerde buğday, arpa, çavdar gibi tahıllarda bulunan glutene karşı gelişen otoantikorların neden olduğu ince bağırsak mukozasında hasar ve malabsorbsiyon ile karakterize otoimmün bir hastalıktır (1). Çölyak hastalı̆̆ı ishal, karın şişliği gibi gastrointestinal sistem bulgularıyla prezente olabileceği izole boy kısalı̆̆ı, depresyon, artrit gibi gastrointestinal sistem dışı bulgularla da prezente olabilir (2). Çölyak hastalı̆̆ının dermatitis herpetiformis ve alopesi gibi bazı farklı deri bulgularıla prezente olabileceği bilinmektedir (3). Ancak literatürde kronik kserozis ile birlikteliğini bildiren bir veri bulunmamaktadır.

$\mathrm{Bu}$ makalede kronik kserozis ile prezente olan ve ileri incelemeler sonucunda çölyak hastalığı tanısı konulmuş bir çocuk hasta sunulmuş ve literatür bilgileri ışığında tartışılmıştır.

\section{OLGU}

On yaşında erkek hasta, yaklaşık 3-4 yıldan beri aralıklarla olan ciltte yaygın kaşıntı ve eklem yerlerindeki kızarıklık ve kuruluk sebebiyle getirildi. Hastanın öyküsünde bu şikayetler ile daha önceden dış merkeze başvurduğu ancak lokal tedavi verildiği, hastanın tedaviden kısa süreli fayda gördüğü ve sonrasında lezyonların tekrar çıktığı öğrenildi. Aralarında akrabalık bulunmayan 35 yaşında sağlıklı baba ve 29 yaşında sağlıklı annenin ikinci çocukları, miadında 3450 gr olarak normal vajinal yol ile doğmuş. Aşıları Sağlık Bakanlığı aşı takvimine uygun olarak yapılmış. Beş yaşında erkek kardeşi sağ ve sağlıklıydı. Soy geçmiş incelemesinde ailesinde bir kalıtsal hastalık veya kronik hastalık olmadı̆̆ öğrenildi.

\footnotetext{
Yazışma Adresi/Address for Correspondence: Melike Arslan, MD, Sağlık Bilimleri Üniversitesi Gülhane Eğitim ve Araştırma Hastanesi, Çocuk Gastroenteroloji Bilim Dalı, General Dr.Tevfik Sağlam Cd. No:1 Posta Kodu: 06010 Etlik, Ankara/Türkiye

E-Posta/E-Mail: melikearslan190@gmail.com || Tel: +90505 2878900

Received/Geliş Tarihi: 16.02.2020 || Accepted/Kabul Tarihi: 18.04.2020

Bu Eser Creative Commons Atıf-Gayriticari 4.0 Uluslararası Lisansı İle Lisanslanmıştır. This work is licensed under a Creative Commons

Attribution-NonCommercial 4.0 International License (CC BY-NC 4.0).
} 
Fizik muayenesinde vücut ağırlığı 24 kg (3-10 persentil), boy $130 \mathrm{~cm}$ (10 persentil) olarak ölçüldü. Ciltte yaygın kserozis, dirsek ve diz eklem yerlerinin ekstansör yüzeyinde kserotik, kaşıntılı lezyonlar mevcuttu (Şekil 1-2). Diğer sistem muayeneleri normal idi. Gelişme geriliği ve kserotik cilt bulguları olan hastanın, atipik bulgularla prezente olan çölyak hastalığı olabileceği düşünülerek bu açıdan incelendi. Laboratuvar incelemelerinde hemoglobin $(\mathrm{Hb})$ 13,1 gr/dl, beyaz küre $8.400 / \mathrm{mm} 3$, platelet $320.000 / \mathrm{mm} 3$ rutin biyokimyasal tetkiklerinde glukoz $101 \mathrm{mg} / \mathrm{dl}$, üre 32 mg/dl, kreatinin 0,55 mg/dl, ast 30U/L, alt $18 \mathrm{U} / \mathrm{L}$ saptandı. Yapılan tetkiklerinde anti doku transglutaminaz Ig A> 200 ve Ig A 80 $\mathrm{mg} / \mathrm{dl}$ olarak ölçüldü. Üst gastrointestinal sistem endoskopik incelemesinde duodenum mukozasında tarak sırtı manzarası mevcuttu. Histopatolojik incelemelerde, duodenum biyopsi örneklerindeki histopatolojik değişikliklerin Modifiye Marsh Sınıflamasına göre tip3c çölyak hastalığı ile uyumlu olduğu rapor edildi (4).

Resim 1. Ciltte yaygın kaşıntılı, kserotik lezyonlar

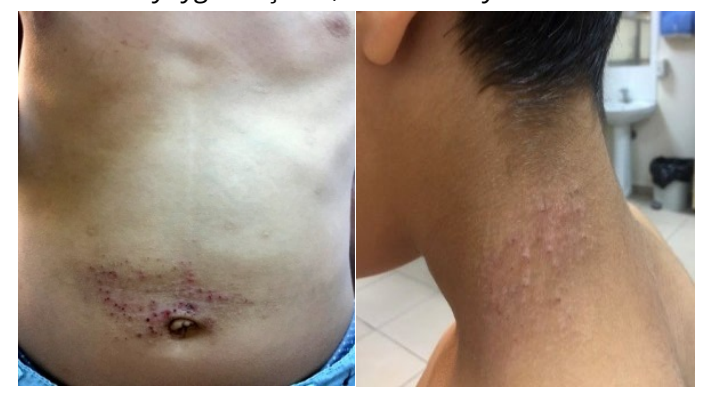

Resim 2. Ekstremitelerin ekstansör yüzeyinde kserozis

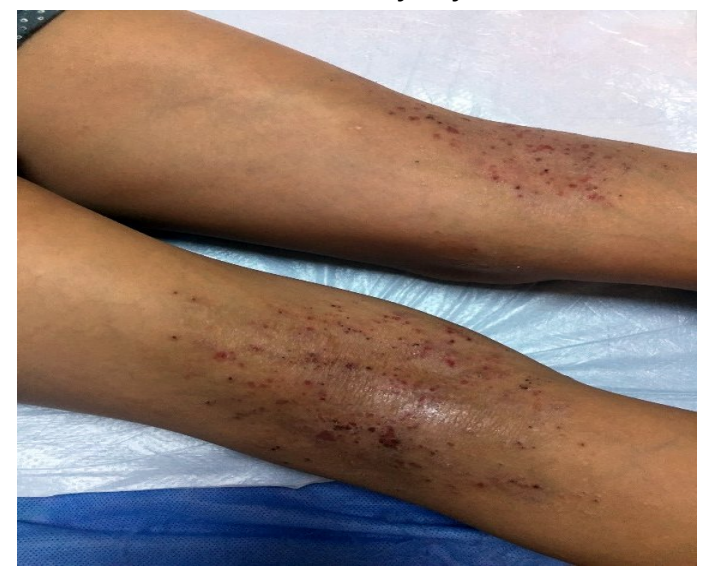

Hastadan deri punch biyopsi planlandı ve immünfloresan incelemede üst dermisteki damarların duvarlarındaki şüpheli IgA ve fokal bazal lineer IgM birikimi saptandı. Hastanın cilt lezyonunun kronik kserozis olduğu saptandı.
Hastaya glutensiz diyet tedavisi ve kserozisi için mometazon furoat ve takrolimus monohidrat içeren pomat başlandı. Hastaya glutensiz diyet tedavisi başlandıktan sonra cilt bulgularında belirgin iyileşme oldu. Halen tedavisinin altıncı ayında olup çocuk gastroenterolojisi ve cildiye polikliniklerinde aylık periyotlarla tedavi izlemi sürmektedir. Çölyak hastalığında deri ve bağırsağın birlikte etkilenmesinin nedenini açıklamaya yönelik çalışmalar sürmektedir. Bilindiği gibi hastalığın patogenezinde genetik ve immünolojik faktörler önemli rol oynamaktadır. Bu immün süreçte doku transglutaminazın hem bağırsakta hem de deride baskın otoantijen olduğu görülmektedir (1). Diğer taraftan villöz atrofiye bağlı olarak gelişen derin malabsorbsiyon nedeniyle pek çok besin ve elementin amilimi azalmaktadır (5). Çölyak hastalığında görülen mukokütanöz bulguların, otoimmün mekanizmaların ve malabsorbsiyonun neden olduğu çoklu besin eksikliklerinden kaynaklandığı düşünülmektedir (5).

Dermatit herpetiformis, çölyak hastalığının en yaygın görülen immün aracılı kütanöz bulgusudur. Bu kaşıntılı, papüloveziküler döküntü histolojik olarak subepidermal kabarcıklanma ve dermal-epidermal bağlantı boyunca granüler IgA birikimi ile karakterizedir. Erişkin çölyak hastalarında çocuk hastalara göre daha sık görülmektedir (3).

Çölyak hastalığının diğer klinik mukokütanöz belirtileri daha non-spesifik olup kaşıntı, kuru iktiyotik ve atrofik cilt, kolay egzematizasyon, hipopigmente ve seyrek saçlar, kırılgan tırnaklar, glossit, melanozis görülebilir. Bu bulguların çoğu malabsorbsiyona ikincil oluşan demir ve çinko eksikliği ile ilişkilidir (3). Malabsorbsiyonlu hastalarda döküntü bazen seboreik dermatit ve psöriazise, bazen egzama, asteatoz ve iktiyoza benzediği bildirilen eritematöz, pullu bir döküntü şeklinde olabilmektedir (5). Kütanöz kserozis, bozulmuş keratinosit proliferasyonu ve farklılaşması, lipit içeriği, hidrasyon, $\mathrm{pH}$ ve sebum üretimi ile karakterize stratum corneumun bir modifikasyonudur. Cilt bariyeri fonksiyonunu etkiler, cilt rahatsızlığına ve estetik kaygılara neden olur, nemlendiriciler ve keratolitikler ile topikal ve semptomatik tedavi edilir (6). Bizim hastamızda ciltte yaygın kaşıntı, kuruluk ve ekstremitelerde egzematöz lezyonlar saptandı. Bu lezyonların, histopatolojik olarak ileri derecede villöz atrofi nedeniyle oluşmuş derin malabsorbsiyonla ilişkili olduğu değerlendirildi. Bu olgu hem dermatologların 
hem de çocuk doktorlarının çölyak hastalığının çeşitli mukokütanöz belirtilerinden haberdar olması gerektiğini; dikkatli bir deri, mukoza, tırnak ve saç muayenesinin çölyak tanısını kolaylaştıracağını göstermektedir (7).

Sonuç olarak çölyak hastalığı sadece gastrointestinal sistem hastalığı olarak düşünülmeyip, deri bulgularıyla da gelebilen bir sistemik hastalık olduğu unutulmadan değerlendirilmelidir. Tekrarlayan ve tedaviye dirençli cilt bulguları olan hastalarda çölyak hastalığının da olası tanılardan biri olabileceği düşünülmeli ve bu yönde ileri incelemeler yapılmalıdır.

Etik; Bu yazıda sunulan olgu için sunulan bilgilerin akademik amaçı kullanımı hakkında detaylı bilgileri de içeren imzalı "Bilgilendirilmiş onam formu" alınmıştır.

Ethics; For the case presented in this article, a signed "informed consent form" was obtained, which includes detailed information about the use of the information presented for academic purposes.

Yazar katkı durumu; Olgunun tanı ve takip süreci; NY, MA, NBT, EÇ, tedavi süreci; NY, MA, NBT, EÇ, Literatür taraması; NY, MA, NBT, EÇ, yazım aşaması; NY, MA, NBT, EÇ

Author contribution status; The concept of the study; NY, MA, NBT, EÇ, design; NY, MA, NBT, EÇ, literature review; NY, MA, NBT, EÇ, collecting and processing data; NY, MA, NBT, EÇ, statistics; NY, MA, NBT, EÇ, writing phase; NY, MA, NBT, EÇ

Yazarlar arasında çıkar çatışması yoktur.

The author declares no conflict of interest.

Finansal Destek: yoktur / Funding : none

doi: ***************

\section{KAYNAKLAR}

1. ESPGHAN Guidelines for the Diagnosis of Coeliac Disease - J Pediatr Gastroenterol Nutr. 2012; 54: 136-160.

2. Balamtekin N, Uslu N, Baysoy G, Usta Y, Demir H, SaltikTemizel IN, Ozen H, Gürakan F, Yüce A. The presentation of celiac disease in 220 Turkish children. Turk J Pediatr. 2010; 52: 239-244.

3. Poon E, Nixon R. Signs, syndromes and diagnoses.Cutaneous spectrum of celiac disease. Aust J Dermatol 2001;42:136-141.

4. Ensari A, Marsh MN. Diagnosing celiac disease: A critical overview.Turk J Gastroenterol. 2019 May;30(5):389-397. doi: 10.5152/tjg.2018.18635

5. Braverman IM. Skin signs of gastrointestinal disease. Gastroenterology2003;124:1595- 1614.

6. Boralevi F, Meledie N'Djong AP, Yao Yoboue P, Faye O, Dieng
MT, Coniquet S, Atadokpede F, Niamba PA, Delarue A, Cazeau C.Regression of cutaneous xerosis with emollient treatment in sub-Saharan African patients.Int J Dermatol. 2017 Apr;56(4):467473. doi: 10.1111/ijd.13454. Epub 2017 Feb 16.

7. Seyhan M, Erdem T, Ertekin V., The Mucocutaneous Manifestations Associated with Celiac Disease in Childhood and Adolescence. Pediatric Dermatology Vol. 24 No. 1 28-33, 2007 